Kodifikasia : Jurnal Penelitian Islam, Vol 15, No. 01 (2021), 19-35

DOI : 10.21154/kodifikasia.v15i1.2659

ISSN : 1907-6371 (Cetak)

ISSN : 2527-9254 (Online)

\title{
PERAN WAKAF UANG DALAM MEMBERDAYAKAN PENDIDIKAN
}

\author{
Syamsuri*, Yusuf Al Manaanu**
}

\begin{abstract}
ABSTRAK:
Tujuan penelitian ini untuk mengetahui peran wakaf uang dalam memberdayakan pendidikan yang sudah teralisasikan di beberapa lembaga wakaf. Hasil penelitian menunjukkan bahwa peran wakaf uang sangat penting dalam memberdayakan pendidikan. Wakaf uang memberi peran terhadap beberapa lembaga wakaf dalam mendukung dan meningkatkan pendidikan secara materil. Peneliti memilih wakaf uang karena perlunya pendayagunaan wakaf uang yang memberi implikasi pada perkembangan pendidikan serta kurangnya sosialisasi pada masyarakat terhadap wakaf uang di Indonesia. Di sisi lain, peneliti ingin mendapat gambaran potensi wakaf uang dan gambaran strategi dalam upaya pengembangan ekonomi umat khususnya dalam bidang pendidikan. Metode yang digunakan dalam penelitian ini adalah metode kualitatif dengan pendekatan analisis deskriptif untuk menjelaskan pelaksanaan wakaf uang dalam memberdayakan pendidikan. Ruang lingkup kegiatan penelitian, keterpaduan terbatas pada Lembaga Wakaf yang memaksimalkan wakaf uang dalam memberdayakan pendidikan di Indonesia, serta bagaimana menyusun model pemberdayaan wakaf uang tunai yang bersinergi dalam bidang pendidikan oleh lembaga wakaf. Selain itu juga untuk mendapatkan penelitian lebih mendalam tentang wakaf uang dan juga mengoptimalkan ke bidang lainnya guna memberdayakan umat.
\end{abstract}

Kata Kunci: Pemberdayaan; Wakaf Uang; Pendidikan

\footnotetext{
* Universitas Darussalam Gontor Ponorogo, email: syamsuri@unida.gontor.ac.id

**Universitas Darussalam Gontor Ponorogo, email: yusuf.almanaanu@gmail.com
} 


\begin{abstract}
:
The purpose of this study was to determine the role of cash waaf in empowering education that has been realized in several waqf institutions. The results showed that the role of cash waqf is very important in empowering education. It gives a role to several waqf institutions in supporting and improving education. Researchers chose cash waqf to utilize cash waqf which implicate the development of education when there is a lack of socialization of it in the community in Indonesia. On the other hand, the researcher wants to get an overview of the potential of cash waqf and a description of the strategy to develop the economy, especially in education. The method used in this research is a qualitative method with a descriptive analysis approach to explaining the implementation of cash waqf in empowering education. The scope of the research was limited on the integration of waqf institutions that maximize cash waqf in empowering education in Indonesia, as well as how to develop a model for empowering cash waqf that synergizes in education by waqf institutions. Also to get more in-depth research on cash waqf and optimize it into other fields to empower people.
\end{abstract}

Keywords: Empowerment; Cash Waqf; Education

\title{
PENDAHULUAN
}

Pendidikan merupakan aspek penting dalam menilai kesejahteraan masyarakat, karena dengan adanya perguruan tinggi masyarakat dapat meningkatkan kualitas hidupnya. Dalam Islam, manusia dikatakan sejahtera jika manusia bisa mencapai kebahagiaan yang bermanfaat baik di dunia dan akhirat. ${ }^{1}$ Pendidikan dalam Islam memiliki kedudukan yang utama, hal ini dibuktikan dari salah satu dari lima syarat yang harus dipenuhi adalah aql (pendidikan), seperti dalam firman Allah dalam QS. At-Taubah (9): 122, terdapat dorongan bagi setiap muslim untuk mencari dan menyebarkan ilmu atau mengajarkan apa yang telah dipelajari kepada orang lain sehingga ilmu tersebut bisa lebih bermanfaat.

Sebagai salah satu aspek yang memiliki peran penting dalam peningkatan kualitas hidup, negara memberikan perhatian khusus pada aspek pendidikan. Menurut UNESCO tingkat anggaran rata-rata negara maju menjadi 5,3\% dari Produk Domestik Bruto (PDB), negara berkembang

${ }^{1}$ Puspita Rachman, "Pemberdayaan Wakaf Tunai Dalam Bidang Pendidikan Pada BMT Hidayatullah Di Surabaya," Ekonomi Dan Terapan 3, no. 8 (2016): 26.

Kodifikasia: Jurnal Penelitian Islam, Volume, 15 No. 1 Tahun 2021 
4,2\% dari PDB, dan Negara terbelakang 2,8\% dari PDB. ${ }^{2}$ Indonesia pada dasarnya termasuk dalam negara berkembang, seharusnya memiliki anggaran pendidikan rata-rata minimal 4\% dari PDB. Namun hal tersebut tidak terjadi di Indonesia. Anggaran pendidikan di Indonesia hanya berkisar 1,4\% dari PDB. Anggaran pendidikan Indonesia bahkan lebih kecil dari rata-rata anggaran pendidikan untuk negara-negara tertinggal. Data di atas menunjukkan bahwa Pemerintah Indonesia belum serius menggarap sektor pendidikan. Ada banyak hal yang menyebabkan pendidikan belum menjadi perhatian utama Pemerintah, salah satunya karena kurang ketersediaan dana untuk pendidikan.

Dalam rangka mendukung terselenggaranya pendidikan yang baik bagi masyarakat, Pemerintah dapat menggunakan dana sebagai modal wakaf dalam mewujudkan pendidikan yang layak bagi rakyatnya. Wakaf dapat memberikan donasi yang tidak sedikit, untuk menjamin kepentingan masyarakat bahkan sangat mungkin menjadi sumber dana dari masyarakat kepada masyarakat. ${ }^{3}$ Seperti yang dijelaskan di atas bahwa aset wakaf tidak hanya sebatas aset tidak bergerak, tetapi bisa berupa surat berharga, uang, logam mulia, dan lain sebagainya.

Kehadiran wakaf sebagai instrumen dalam memberdayakan umat secara menyeluruh dianggap penting dimana nazir berperan untuk mengornasisir potensi dan ketrampilan dalam elemen masyarakat. Sehingga potensi yang dimiliki masyarakat dapat diberdayakan sesuai potensi wakaf yang ada, baik wakaf tidak bergerak maupun yang bergerak. ${ }^{4}$ Wakaf mempunyai peran penting dan strategis dalam perkembangan umat yang ajarannya bukan hanya pada dimensi normatif tetapi juga sosial, karena masalah-masalah sosial masyarakat dapat diatasi dengan wakaf. Pemberdayaan aset wakaf bisa menjadi sarana pengembangan ekonomi bagi masyarakat. ${ }^{5}$ Adapun yang dimaksud ekonomi dalam wakaf ini merupakan sisi material-finansial untuk memenuhi kebutuhan dasar manusia yang dihasilkan dari pengelolaan dan pengembangan wakaf. Karenannya harta wakaf perlu dimanfaatkan degan produktif untuk menciptakan kesempataan dan peluang dalam pemanfaatan harta wakaf yang lebih luas, seperti membuka lapangan kerja baru, serta mengadakan fasilitas sebagai pemberdayaan usaha masyarakat kecil dan menengah (UKM).

${ }^{2}$ Sri Herianingrum, Muhammad Nafik HR, and Sri Iswati, "Cash Waqf Empowerment Model in Improving the Quality of Education At Waqf Institutions," J. Islam. Fin 2, no. 2 (2016): 28.

${ }^{3}$ Fajar Hidayanto, "Wakaf Tunai Produktif," Mukaddimah XV, no. 26 (2009): 16. 33.

4 Aisa Manilet, "Wakaf Tunai Dan Pemberdayaan Umat," Tahkim IX, no. 2 (2013):

${ }^{5}$ Aji Damanuri, "Efektivitas Dan Efisiensi Pemanfaatan Harta Wakaf Majlis Wakaf Pimpinan Daerah Muhammadiyah Ponorogo," Kodifikasia 6, no. 1 (2012): 79. 
Wakaf produktif adalah aset berupa pemberian sesuatu yang dapat diusahakan atau digilir untuk kemaslahatan umat, baik berupa uang tunai maupun surat berharga. Namun dalam melakukan hal tersebut memang terdapat beberapa perbedaan antara ulama Al-Syafi'i dan Hanafi. AlSyafi'i mengemukakan jika harta yang telah dikirim tidak boleh ditarik atau diminta kembali, sedangkan menurut ulama hanafi, harta tersebut harus ditarik kembali. Wakaf uang hanya dapat digunakan dan disalurkan untuk keperluan sesuai syariat. Nilai wakaf wajib dijamin keabadiannya, tidak boleh dijual belikan, diwariskan, maupun dihibahkan. ${ }^{6}$ Terlepas dari perbedaan wakaf tersebut diharapkan dapat memberikan manfaat yang luas bagi masyarakat secara berkelanjutan. ${ }^{?}$

Peresmian Gerakan Nasional Wakaf Uang oleh Presiden Joko Widodo pada 25 Januari 2021 menunjukkan betapa besarnya potensi wakaf uang yang seharusnya bisa dikumpulkan, karena potensi aset wakafnya yang setiap tahunnya mencapai 2.000 triliun hanya dapat menembus angka 188 triliur pada saat ini. Lebih lanjut ia menyampaikan bahwa wakaf uang bukan hanya meningkatkan kepedulian, pelajaran, dan rujukan masyarakat terhadap keuangan syariah, tetapi juga meningkatkan perhatian masyarakat untuk mengatasi kesenjangan dan kemiskinan. ${ }^{8}$ Wakaf uang selain memiliki efek bola salju juga memiliki keunggulan lain, yaitu dapat digunakan secara fleksibel dan lebih luas jangkauannya sehingga programprogram pemberdayaan masyarakat melalui dana wakaf dapat lebih optimal dibandingkan zakat, infak, dan sedekah. ${ }^{9}$ Hal ini dibuktikan dengan keberadaan sekolah di lembaga wakaf.

Dalam penelitian Aminu dan Azreen dengan judul "Implementation of Cash Waqf a Solution for Financing Almajiri System Education in Nigeria" bahwa dalam pemerintah, organisasi keagamaan dan orang-orang kaya mendirikan wakaf uang untuk mengatasi masalah dan tantangan terhadap sistem pendidikan Almajiri. Penerapan wakaf tunai terbukti mampu menjadi solusi dalam mensponsori sistem pendidikan Almajiri dalam mengajarkan Al Qur'an dan pengetahuan Islam. ${ }^{10}$

${ }^{6}$ M. Abdul Mannan, Teori Dan Praktik Ekonomi Islam (Yogyakarta: PT. Dana Bhakti Wakaf, 2002), 33.

${ }^{7}$ Didin Hafidhudin, Agar Harta Berkah Dan Bertambah: Gerakan Membudayakan Zakat, Infak, Sedekah, Dan Wakaf (Jakarta: Gema Insani Press, 2007), 90.

8 https://nasional.kompas.com/read/2021/01/25/12085161/presiden-jokowiresmikan-gerakan-nasional-wakaf-uang-dan-brand-ekonomi. Diakses pada 2 Februari 2021.

${ }^{9}$ Iza Hanifuddin, "Res Nullius Waqf: Dinamika Relasi Penguasaan Wilayah Oleh Negara Dan Pemilikan Aset Tanah Wakaf Oleh Umat Serta Ide Prospektif Penguatan Fungsi Dan Daya Guna Wakaf,” Kodifikasia 12, no. 1 (2018): 78.

${ }^{10}$ Aminu Yaqubu and Azreen hamiza binti Abdul Aziz, "Implementation of Cash Waqf as a Solution for Financing Almajiri System Education in Nigeria," International

Kodifikasia: Jurnal Penelitian Islam, Volume, 15 No. 1 Tahun 2021 
Penelitian Iqbal Imari dan Syamsuri dengan judul "Pemberdayaan Waqf Produktif sebagai Media Pembangunan Ekonomi Pesantren: Satu Analisa Mekanisme Pelaksanaannya di Pesantren Wali Songo Ngabar" dengan kesimpulan pengelolaan wakaf produktif di pesantren Wali Songo dapat memberdayakan ekonomi telah dirancang dan dikonsep dengan rapi dan terstuktur dalam jangka pendek maupun panjang serta melakukan pengorganisasian melaui manajemen penghimpunan, investasi, dan penyaluran manfaat wakaf. Untuk menjalankan program tersebut lembaga wakaf bersinergi dengan lembaga lainnya dalam mengelola dan mengembangakan harta wakaf. ${ }^{11}$

Dan penelitian Jaharuddin dengan judul "Potensi Wakaf Uang untuk Pendidikan (Studi Kasus FEB UMJ)" dengan kesimpulan (1) pahalanya terus mengalir sekalipun yang berwakaf sudah meninggal; (2) terus menerusnya manfaat walaupun generasi berganti; (3) wakaf mempunyai watak abadi; (4) perlu diperbanyak yang mengelola wakaf secara produktif; (5) menjadi solusi dalam bidang pendidikan dan jaminan sosial; (6) pengelolaan wakaf merupakan pengelolaan manajemen strategis suatu kampus; (7) fleksibel. ${ }^{12}$

Berdasarkan hal tersebut, menarik untuk diteliti bagaimana model pemberdayaan wakaf tunai dalam meningkatkan mutu pendidikan di lembaga wakaf. Sangat menarik untuk dicermati karena masih banyak masyarakat Indonesia yang belum paham benar tentang wakaf secara keseluruhan. Di samping itu masih sedikit seorang peneliti yang menjadikan wakaf uang sebagai topik penelitiannya, sehingga tidak banyak sumber yang dapat dijadikan bukti bahwa wakaf uang memiliki potensi yang sangat besar dalam menunjang semua aspek kehidupan. Penelitian ini berfokus pada bagaimana model pemberdayaan wakaf tunai dalam meningkatkan kualitas pendidikan di lembaga wakaf.

Dalam penelitian ini menggunakan penelitian kualitatif. Alasan menggunakan pendekatan tersebut, yaitu untuk mengetahui bagaimana peran wakaf tunai dalam memberdayakan pendidikan. Kemudian berdasarkan penjelasan yang telah dipaparkan pada latar belakang masalah untuk merujuk pada rumusan masalah, serta tujuan penelitian, pendekatan yang digunakan dalam penelitian ini menggunakan pendekatan penelitian kualitatif. ${ }^{13}$ Dalam penelitian ini yang dimaksud dengan fenomena tersebut

Journal of Psychosocial Rehabilitation 23, no. 4 (2019): 883.

${ }^{11}$ Iqbal Imari and Syamsuri, "Pemberdayaan Wakaf Produktif Sebagai Media Pembangunan Ekonomi Pesantren," Islamic Economic Journal, 2017, 30.

${ }^{12}$ Jaharuddin, "Potensi Wakaf Uang Untuk Pendidikan (Studi Kasus FEB UMJ)," Ikraith-Humaniora 2, no. 2 (2018): 93.

${ }^{13}$ Robert Yin, Studi Kasus Desain Dan Metode (Jakarta: PT Rajagrafindo Persada, 2011), 18.

Kodifikasia: Jurnal Penelitian Islam, Volume, 15 No. 1 Tahun 2021 
adalah semua kegiatan terkait pemanfaatan wakaf tunai yang dikelola oleh badan atau lembaga zakat yang mengelola dana wakaf tunai di bidang pendidikan.

\section{PEMBAHASAN \\ Konsep Wakaf Uang}

Kata wakaf berasal dari bahasa Arab waqafa yang mempunyai arti diam di tempat, menahan, berhenti, atau tetap berdiri. ${ }^{14}$ Mundzir Qahf mendefinisikan wakaf merupakan pemberian harta atau benda produktif tanpa adanya kepentingan pribadi yang hasil dan manfaatnya digunkan sesuai tujuan wakaf, baik untuk kepentingan pribadi maupun umum dalam lingkup masyarakat dan agama serta lebih luas lagi. ${ }^{15}$ Abu Bakar dalam Farid menjelaskan wakaf sebagai usaha menahan harta agar tidak bisa dijual, diwariskan, atau dihibahakan, serta hasil dari wakafnya diberikan kepada penerima yang berhak. ${ }^{16}$

Harta wakaf tidak hanya terbatas pada benda tidak bergerak, tetapi juga terhadap benda bergerak atau uang. Pemanfaatan wakaf uang sudah digunakan dalam rentang waktu cukup lama pada masa pemerintah Islam. Mannan menjelaskan penerapan wakaf uang sudah ada sejak masa kekhalifahan Utsmaniyah. Pada masa kekhalifahan Ottoman wakaf uang juga telah dikenal di berbagai wilayah. ${ }^{17}$ Wakaf uang merupakan wakaf yang dilaksanakan seseorang, kelompok, dan lembaga atau badan hukum berbentuk uang tunai termasuk di dalamnya surat berharga seperti saham, cek, dan lainnya. ${ }^{18}$ Madzhab Hanafi dan Maliki, serta beberapa ulama madzhab Syafi'i mengemukakan diperbolehkannya wakaf uang seperti yang dijelaskan Al Mawardi dalam riwayat Abu Tsaur tentang kebolehan wakaf dinar dan dirham. ${ }^{19}$

${ }^{14}$ Wahbah Al-Zuhaili, Al-Fiqh Al-Islami Wa Adillatuhu (Damaskus: Dar al-Fikr alMu'asir, 1984), 7599.

${ }^{15}$ Mundzir Qahaf, Sanadât Al-Ijârah, Al-Ma'had Al-Islâmy Li Al-Buhûts Wa At-Tadrîb (Cairo: Dar as-Salam, 1995), 64.

${ }^{16}$ Farid Wadjdy Mursyid, Wakaf 83 Kesejahteraan Umat (Filantripi Islam Yang Hampir Terlupakan) (Yogyakarta: Pustaka Pelajar, 2007), 30.

${ }^{17}$ Mannan, Sertifikat Wakaf Tunai, Sebuah Inovasi Instrumen Keuangan Islam (Jakarta: CIBER, 2001), 93.

${ }^{18}$ Departemen Agama RI, Pedoman Pengelolaan Wakaf Tunai (Jakarta: Direktorat Jenderal Pengembangan Zakat dan Wakaf Direktorat Bimbingan Masyarakat Islam dan Penyelenggaraan Haji, 2015), 1.

${ }^{19}$ Al Mawardi and Abi al-Hasan Ali bin Muhammad bin Habib, Al Hawi Al Kabir (Beirut: Dar al Fikr, 1994), 379.

Kodifikasia: Jurnal Penelitian Islam, Volume, 15 No. 1 Tahun 2021 
Penetapan Komisi Fatwa majelis Ulama Indonesia (MUI) yang dilaksankan tanggal 11 Mei 2002 tentang wakaf uang, adalah berikut:

1. Wakaf uang (Waqf al Nuqud/Cash Waqf) merupakan wakaf yang dilaksanakan oleh orang, golongan, organisasi maupun badan hokum berupa uang tunai.

2. Yang dimaksud ke dalam pengertian uang termasuk surat-surat berharga.

3. Wakaf uang hukumnya dibolehkan (jaiz).

4. Wakaf uang hanya diberikan dan digunakan untuk kepentingan yang dibolehkan syariat.

5. Nilai pokok uang wajib dijamin keabadiannya, tidak boleh dijual belikan, diwariskan atau dihibahkan.

Dalam Undang-Undang Republik Indonesia No. 4 Tahun 2004 tentang wakaf, pada pasal 16 ayat (1) disebutkan bahwa harta wakaf berupa benda tidak bergerak maupun benda bergerak. Dalam ayat (3) dijelaskan bahwa benda bergerak merupakan harta benda yang tidak akan habis karena dikonsumsi, yaitu meliputi:

1. Uang;

2. Logam mulia;

3. Surat berharga;

4. Kendaraan;

5. Hak atas keakayaan intelektual;

6. Hak sewa;

7. Dan benda bergerak lainnya yang sesuai dengan ketentuan syariah dan peraturan undang-undang yang berlaku.

\section{Konsep Pemberdayaan}

Pemberdayaan secara epistimologis berati kekuasaan (power) yang berasal dari kata "daya" dan secara terminologis memberikan kekuasaan/kekuatan dari kaum tidak berdaya menuju kaum yang lebih berdaya. Pemberdayaan juga diartikan sebagai usaha mewujudkan kemandirian sebagai kekuatan manusia yang memiliki sumber daya alam dan ketrampilan hidup dengan proses pembinaan, bimmbingan, maupun bantuan teknis lainnya. ${ }^{20}$

Adapun definisi/pengertian dari pemberdayaan menurut beberapa pakar ialah sebagai berikut:

1. Menurut Webster dalam Oxford Dictionary, pemberdayaan dari kata empower memuat dua pengertian. Pertama berarti to give power or authority (menyerahkan kekuasaan, melimpahkan kekuasaan, atau memberikan

${ }^{20}$ Onny S. Prijono and A.M.W. Pranarka, Pemberdayaan: Konsep, Kebijakan Dan Implementasi (Jakarta: CSIS, 1996), 3.

Kodifikasia: Jurnal Penelitian Islam, Volume, 15 No. 1 Tahun 2021 
pengaruh kepada kelompok lain). Kedua adalah to give ability to inability (memberikan kemampuan terhadap pihak tidak berdaya). ${ }^{21}$

2. Sunyoto Usman dalam bukunya "Pengorganisasian dan Pengembangan Masyarakat" menyatakan pemberdayaan masyarakat merupakan upaya meningkatkan sesuatu untuk menjadi mandiri (community self-reliance). ${ }^{22}$ Abu Di dalam proses ini untuk mendampingi dalam menganalisis kesulitan yang dialami, didukung untuk menemukan solusi dalam mengahadapi masalah, dan diberikan pengarahan strategi untuk memanfaatkan sumber daya alam yang ada.

3. Eddy Papilaya dikutip Zubaidi menerangkan bahwa pemberdayaan adalah upaya mengembangkan potensi masyarakat dengan memberi dorongan, motivasi, dan membangun kemampuan yang dimiliki dengan tindakan dalam kehidupan secara nyata. ${ }^{23}$

Dari pengertian pemberdayan di atas, dapat diringkas bahwa pemberdayaan merupakan upaya seseorang atau kelompok dalam melaksanakan kegiatan berupa pendampingan ketrampilan, peningkatan kemampuan dan potensi demi terciptanya masyarakat yang mandiri dan berdaya dalam segi ekonomi, pendidikan, sosial, dan budaya dalam menyelesaikan berbagai masalah yang dihadapi.

\section{Peran Wakaf Uang dalam Memberdayakan Pendidikan}

Menurut Mannan uang juga termasuk benda bergerak yang hakekatnya termasuk salah satu bentuk wakaf yang diperbolehkan secara syariah Islam. Sehingga pada saat ini muncul pemahaman di sekitar masyarakat dengan istilah wakaf uang (cash waqh). ${ }^{24}$ Sejauh ini wakaf hanya terbatas pada benda fisik yang pemanfaatannya belum memberikan dampak signifikan terhadap kesejahteraan ekonomi masyarakat. Banyaknya wakaf di Indonesia yang masih berupa benda nyatanya belum memberikan kontribusi dalam mengatasi kemiskinan. ${ }^{25}$ Penerapan wakaf uang pada masa sekarang dalam bentuk wakaf produktif jika dikelola dengan maksimal memiliki keunggulan lebih besar dari wakaf tradisonal, yaitu benda bergerak maupun tidak bergerak. Harta wakaf selama ini masih identik dengan sekolah, rumah

${ }^{21}$ Tjahta Supriyatna, Strategi Pembangunan Dan Kemiskinan (Jakarta: Rineka Cipta, 2000), 69.

${ }^{22}$ Abu Huraerah, Pengorganisasian $\mathbb{E}$ Pengembangan Masyarakat (Bandung: Humaniora, 2008), 87.

${ }^{23}$ Zubaedi, Wacana Pembangun Alternatif: Ragam Prespektif Pembangunan Dan Pemberdayaan Masyarakat (Jakarta: Ar Ruzz Media, 2007), 42.

${ }^{24}$ Mannan, Teori Dan Praktik Ekonomi Islam, 15.

${ }^{25}$ Ahmad Syakir, "Pemberdayaan Ekonomi Umat Islam Indonesia Melalui Wakaf Produktif," Al-Intaj, 2016, 38.

Kodifikasia: Jurnal Penelitian Islam, Volume, 15 No. 1 Tahun 2021 
sakit, dan kuburan. ${ }^{26} \mathrm{Hal}$ ini menunjukkan bahwa potensi wakaf uang perlu dipahamkan kepada masyarakat sebagai sumber dana untuk memenuhi kesejahteraan masyarakat dalam bidang ekonomi, sosial, dan pendidikan.

Asumsi Nasution tentang potensi wakaf uang di Indonesia dengan jumlah penduduk Muslim sebanyak 10 juta jiwa dengan penghasilan antara Rp. 500.000 - Rp. 1.000 .000 per bulan yang berkontribusi. Maka dapat diprediksi wakaf uang yang terkumpul mencapai 250 juta per bulan, atau 3 triliun per tahun. Dengan penjelasan sebagai berikut: ${ }^{27}$

\section{Tabel . Potensi Wakaf Uang}

\begin{tabular}{|l|l|l|l|l|}
\hline $\begin{array}{c}\text { Penghasilan } \\
\text { Per Bulan }\end{array}$ & $\begin{array}{c}\text { Jumlah } \\
\text { Muslim } \\
\text { (Jiwa) }\end{array}$ & \multicolumn{1}{|c|}{$\begin{array}{c}\text { Wakaf } \\
\text { Per Bulan (Rp) }\end{array}$} & $\begin{array}{c}\text { Potensi } \\
\text { Wakaf Uang } \\
\text { Per Bulan } \\
\text { (Rp) }\end{array}$ & $\begin{array}{c}\text { Potensi Wakaf } \\
\text { Uang Per } \\
\text { Tahun (Rp) }\end{array}$ \\
\hline Rp. 500.000 & 4 Juta & 5.000 & 20.000 .000 & 240.000 .000 \\
\hline $\begin{array}{l}\text { Rp. 1 Juta - 2 } \\
\text { Juta }\end{array}$ & 3 juta & 10.000 & 30.000 .000 & 360.000 .000 \\
\hline $\begin{array}{l}\text { Rp. 2 Juta - 5 } \\
\text { Juta }\end{array}$ & 2 Juta & 50.000 & 100.000 .000 & 1.200 .000 .000 \\
\hline $\begin{array}{l}\text { Rp. 5 Juta }- \\
\text { 10 Juta }\end{array}$ & 1 Juta & 100.000 & 100.000 .000 & 1.200 .000 .000 \\
\hline Total & & & & 3.000 .000 .000 \\
\hline
\end{tabular}

Sumber: Nasution 2005

Mohsin mengemukakan dalam seminarnya di IIUM akan potensi wakaf di Indonesia yang mencapai \$ 14 Milyar per tahun. Presentase ini lebih tinggi dari Negara Malaysia (\$ 1,4 Milyar), Mesir (\$ 6,5 Milyar), dan Pakistan (\$8 Milyar). Hal ini menunjukkan akan besarnya wakaf uang yang belum nampak kontibusinya sehingga perlu pengelolaan yang lebih baik. ${ }^{28}$

Sistem Informasi Wakaf (SIWAK) mencatat dari 52.163,20 hektar luas tanah wakaf di Indonesia, namun baru 32.261,77 hektar atau 60,61\% sudah bersertifikat, sehingga sebagian tanah banyak yang terabaikan. ${ }^{29}$ Data Pusat Statistik mencatat rakyat Indonesia jumlahnya mencapai 268,07 juta jiwa di tahun 2019 dan sebanyak 25,67 juta jiwa atau 9,22\% mengalami

\footnotetext{
${ }^{26}$ Faisal, "Analisis Hukum Penggunaan Dana Wakaf Tunai Untuk Pembangunan Infrakstruktur," De Lega Lata: Jurnal Ilmu Hukum 5, no. 2 (2020): 199.

${ }^{27}$ Mustafa Edwin Nasution, Wakaf Uang Dan Sektor Volunteer (Jakarta: Pusat Kajian Timur Tengah dan Islam Universitas Indonesia, 2005), 78.

${ }^{28}$ Magda Ismail Abdel Mohsin, "The Institution of Waqf : A Non- Profit Institution to Financing the Needy Sectors, Paper Presented to a Conference Realities"," in Research and Development: The Bridge between Ideals and Realities (IIUM International Conference on Islamic Banking and Finance, 2007).

${ }^{29}$ http://siwak.kemenag.go.id/. Diakses 4 Januari 2021.
} 
masalah kemiskinan. ${ }^{30}$ Melihat presentase tersebut mestinya potensi wakaf uang dapat dimanfaatkan untuk menyejahterakan umat dan mengatasi kebutuhan umat di Indonesia. ${ }^{31}$
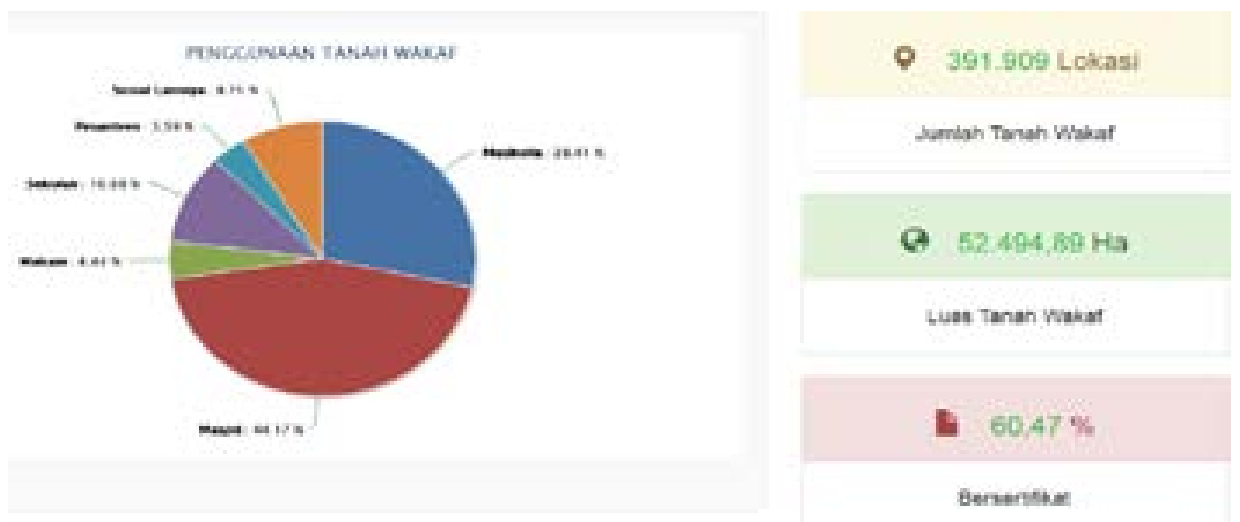

Gambar. Sistem Informasi Wakaf Kemenag

Wakaf terbukti mampu menjadi penanggulangan kemiskinan dan peningkatan taraf hidup masyarakat di segala bidang. Dengan pengelolaan profesional menjadikan wakaf terjaga nilainya hingga berumur ratusan bahkan ribuan tahun. Seperti yang dilaksanakan di Universitas Al Azhar Kairo Mesir yang berhasil memberdayakan wakaf dalam bidang pendidikan yang didirikan $950 \mathrm{M}$ dan memberikan beasiswa pendidikan untuk mahasiswa dari seluruh penjuru dunia. Hingga saat ini Al Azhar bukan hanya fokus dalam bidang pendidikan melainkan mengembangkan pengelolaan rumah sakit, perkebunan, hotel, dan usaha lainnya sehingga meberikan manfaat lebih dari 400 ribu mahasiwa dengan biaya gratis, memberi upah 11 ribu dosen, dan mengirimkan ilmuwan dan ulama di berbagai Negara seluruh dunia. ${ }^{32}$ Selain digunkan untuk kepentingan internal, universitas tersebut juga mengelola beberapa perusahaan di terusan Suez yang hasilnya hanya untuk keperluan pendidikan. Bahkan pemerintah Mesir meminjam hasil dana wakaf universitas Al Azhar untuk operasioanal. ${ }^{33}$

${ }^{30}$ BPS, "Statistik Indonesia Statistical Yearbook Of Indonesia 2020," Badan Pusat Statistik, 2020.

${ }^{31}$ Syamsuri, Perdi Fauji Rohman, and Aris Stianto, "Potensi Wakaf Di Indonesia (Kontribusi Wakaf Dalam Mengurangi Kemiskinan)," Malia: Jurnal Ekonomi Islam 4, no. 1 (2020): 81.

${ }^{32}$ Komite Nasional Keuangan Syariah, "Optimalisasi Wakaf Produktif Untuk Kesejahteraan Umat," INSIGHT, September 2019, 3.

${ }^{33}$ Amir Mu'alim, "Pengaruh Pengelolaan Wakaf Di Mesir Terhadap Pengelolaan Harta Wakaf Di Indonesia (Studi Terhadap Ijtihad Dalam Pengelolaan Wakaf Pendidikan Di UII Dan Pondok Modern Gontor)," Akademika 20, no. 1 (2015): 114.

Kodifikasia: Jurnal Penelitian Islam, Volume, 15 No. 1 Tahun 2021 
Selain Universitas Al Azhar Mesir, konsep pengelolaan wakaf diadobsi Harvard dalam menginvestasikan dana abadi (endowment found) yang jumlahnya mencapai \$36,4 miliar, atau setara dengan $\mathrm{Rp} 440$ triliun. Dana tersebut dikelola di berbagai sector keuangan dan sektor ril, dan diinvestasikan di berbagai proyek infrsatuktur dan energi, kemudian hasilnya dimanfaatkan sebagai pengembangan Harvard University dengan memberikan 65\% mahasiswanya beasiswa dengan rata-rata \$ 46 ribu dolar per tahun. ${ }^{34}$

Saat ini di Indonesia banyak terdapat lembaga pendidikan yang berkembang pesat dengan adanya program pemberdayaan wakaf. Seperti yang dilaksanakan di Pondok Modern Darussalam Gontor (1926), yang telah diwakafkan tahun 1958 berupa benda bergerak maupun tak bergerak..$^{35}$ PMDG mengembangkan pengelolaan asset wakaf dan pemanfaatannya tidak terbatas pada aspek ibadah, namun peningkatan pendidikan, ekonomi, dan kesejahteraan umat. ${ }^{36}$ PMDG mempunyai cita-cita mengikuti Universitas Al Azhar yang mampu memberikan beasiswa bagi kader-kader umat dari berbagai penjuru dunia untuk belajar melalui hasil tanah wakafnya. ${ }^{37}$

Pondok Modern Tazakka (2012) dengan menyediakan konter zakat dan wakaf di serambi masjid Az Zaky untuk memudahkan muhsinin dan wakif dalam menyalurkan wakaf tunainya untuk intesitas kegiatan keumatan. ${ }^{38}$ Di PM Tazakka ada enam jenis wakaf, yaitu: wakaf asset, wakaf tunai, wakaf uang, wakaf manfaat, wakaf profesi, dan wakaf pengalihan hak. ${ }^{39}$ PM Tazakka menggalakkan program fundraising ZISWAF (Zakat, Infaq, dan Wakaf) untuk menyangga ekonomi pondok yang didalamnya terdapat pengembangan system pendidikan mandiri dan modern dengan menyiapkan sumber daya manusia unggul dengan finansial cukup..$^{40}$

Pondok Pesantren Tabuireng (1899) dikelola oleh yayasan Hasyim Asyari dan menjelma sebagai sumber pemasukan pondok sampai 90\%,

${ }^{34}$ Muhammad Munadi, "Pengelolaan Endowment Fund Di Perguruan Tinggi Malaysia: Studi Kasus Di Universitas Teknologi Malaysia,” Al Ulum 17, no. 2 (2017): 30.

35 Jarman Arroisi and Syamsuri, "Management Wakaf Pondok Modern Darussalam Gontor: Analisis Model Pemeliharaan, Pengembangan Wakaf Dan Kesejahteraan Umat," Ijtihad: Jurnal Hukum Dan Ekonomi Islam 14, no. 2 (2020): 155.

${ }^{36}$ Achmad Siddiq, "Wakaf Produktif Dan Problematikanya Di Dunia Pesantren," Millah XI, no. 1 (2011): 282.

${ }^{37}$ Arroisi and Syamsuri, "Management Wakaf Pondok Modern Darussalam Gontor: Analisis Model Pemeliharaan, Pengembangan Wakaf Dan Kesejahteraan Umat," 171.

${ }^{38}$ Nurwinsyah Rohmaningtyas, "Pengumpulan Wakaf Berbasis Pesantren: Studi Kasus Di Pondok Modern Darussalam Gontor Dan Pondok Modern Tazakka," Adilla 1, no. 1 (2018): 11.

${ }^{39}$ Farid Izda Iskandar, "Fundraising Strategy of Cash Waqf in Pondok Modern Tazakka in 2019," Journal of Islamic Economics and Philanthropy (JIEP) 02, no. 04 (2019): 557.

${ }^{40}$ Muhammad Fauzi, "Fundraising Ziswaf Dan Kewirausahaan Di Pondok Pesantren Modern Tazakka, Batang, Jawa Tengah,” JBE Jurnal Bingkai Ekonomi 4, no. 1 (2019): 64. 
sehingga para santri dan mahasantri dapat merasakan manfaat dari wakaf produktif tersebut, ${ }^{41}$ serta berbagai yayasan lainnya yang berkembang pesat dengan pola pemanfaatan wakaf. Aset wakaf uang yang terdapat di Ponpes Tebuireng kurang lebih 6.480.294.000 dan diwujudkan sebagai pengembangan pendidikan serta investasi dan pengembangan asset wakaf. ${ }^{42}$ Ponpes tersebut mempunyai badan hukum dalam upaya melaksanakan penggalangan dana mandiri agar tidak bertumpu pada pihak swasta atau pihak manapun. Yayasan Hasyim Asyari tidak berfokus hanya pada pendidikan semata melainkan kontribusinya dalam sektor sosial dan ekonomi terhadap warga sekitar. ${ }^{43}$

Selain lembaga dan yayasan pendidikan, organisasi Nahdlatul Ulama dan Muhammadiyah sebagai organisasi terbesar di Indonesia juga berperan dalam memberdayakan wakaf dalam bidang pendidikan, sosial, kesehatan, dan ekonomi masyarakat. Pengurus Besar Nahdlatul Ulama (PBNU) mempunyai peran aktif dalam mengelola lahan wakaf agar lebih produktif. Sebagai contoh adalah Lembaga Wakaf dan Pertanahan Nahdlatul Ulama (LWNPU) yang merilis program Lembaga Wakaf Nusantara (LWNU) pada tahun 2010. Program ini mengembangkan dana wakaf sebagai bentuk "investasi akherat" yang diproduktifkan dan sifatnya kekal nilainya. Dana LWPNU ini nantinya diproyeksikan dalam bidang pendidikan, ekonomi masyarakat, dan menanggulani kemiskinan. ${ }^{44}$

Muhammadiyah mulai melaksanakan pengelolaan wakaf sejak ditunjuknya organisasi tersebut menjadi nadzir pada tahun 1927. Majelis Wakaf dan Kehartabendaan yang berada di tingkat pusat, wilayah, daerah, cabang, dan ranting menjadi penanggung jawab dalam mengelola dan mengatur segala hal yang berkaitan dengan wakaf secara khusus supaya dapat terlaksana dengan baik. ${ }^{45}$ Salah satu contohnya adalah pengelolaan wakaf yang dilaksanakan Majelis Wakaf dan Kehartabendaan mempunya kewenangan atas pemanfaatan dan pengembangan tanah maupun asset wakaf. Dengan pengembangan wakaf yang maksimal akan memberikan manfaat terhadap kemaslahatan umat. Tanah wakaf yang berada di kota

${ }^{41}$ Muhammad Widyarta Wijaya and Raditya Sukmana, "Peran Wakaf Produktif Dalam Pemberdayaan Kemandirian Ekonomi Pondok Pesantren (Studi Kasus Pesantren Tebuireng Yayasan Hasyim Asyari Jombang),” Teori Dan Terapan 6, no. 5 (2019): 1077.

${ }^{42}$ Miftahul Huda, "Wakaf Dan Kemandirian Pesantren Dari Tebuireng Hingga Gontor," Islamica 7, no. 1 (2012): 2020.

${ }^{43}$ Wijaya and Sukmana, "Peran Wakaf Produktif Dalam Pemberdayaan Kemandirian Ekonomi Pondok Pesantren (Studi Kasus Pesantren Tebuireng Yayasan Hasyim Asyari Jombang)," 1074.

${ }^{44}$ https://www.nu.or.id/post/read/24089/lembaga-wakaf-luncurkan-lumbung-wakafuang. Diakses pada 5 Januari 2021.

${ }^{45}$ http://wakaf.muhammadiyah.or.id/content-3-sdet-sejarah.html. Diakses pada 7 Januari 2021.

Kodifikasia: Jurnal Penelitian Islam, Volume, 15 No. 1 Tahun 2021 
Yogyakarta seluas $235.575 \mathrm{~m} 2$ memiliki 584 persil yang dimanfaatkan untuk pembangunan masjid, mushola, rumah sakit, gedung, kantor, tempat usaha, dan manfaat lainnya. ${ }^{46}$ Pola pengembangan ini terbukti mampu menjadi instrument penting dalam mengabdi pada Negara guna memberi dukungan terhadap bidang sosial, ekonomi, dan khusunya pendidikan.

Melihat besarnya potensi pendanaan Wakaf di Indonesia, maka harus ada sinergi antara Badan Wakaf Indonesia (BWI) dengan Lembaga Wakaf Swasta. Mengingat besarnya potensi wakaf yang belum terlaksana belum maksimal, maka kontribusi pengembangan potensi wakaf BWI dalam bentuk usulan aturan yang diajukan kepada pemerintah, guna memberikan payung hukum wakaf bagi masyarakat yang ada di Indonesia. Penugasan, pelaksanaan, dan wakaf idealnya aturan dan pengawasan dilakukan oleh BWI. ${ }^{47}$ Potensi dana yang sangat besar di lembaga pemerintah maupun swasta perlu dimaksimalkan sebaik mungkin dan disalurkan untuk keperluan pembangunan, pendanaan, dan pendidikan. Sehingga pemberdayaan wakaf terhadap pendidikan mampu menunjang masyarakat lebih luas tanpa membebankan biaya demi terwujudnya pendidikan yang bermutu dan berkualitas untuk membangun bangsa lebih maju.

\section{PENUTUP}

Wakaf uang perlu dikembangkan dan dikelola dengan baik sebagai potensi sumber dana umat. Agar menghasilkan manfaat yang optimal perlu dikembangakan dan didayagunakan secara professional dan memberikan manfaat maksimal dalam memberdayakan masyarakat khususnya dalam bidang pendidikan. Dengan memproduktifkan pengelolaan wakaf diharapkan mampu membantu pemerintah untuk menyelesaikan masalah yang ada. Pemberdayaan wakaf uang merupakan kegiatan yang berdimensi sosial untuk mengabdikan diri terhadap maslahat umat dengan niat mencari ridho Allah. Upaya tersebut bertujuan meningkatkan kesejahteraan dan membantu mereka dari ketidakberdayaan menuju masyarakat yang lebih berdaya dan mampu berkompetisi dalam kehidupannya. Hasil pencapaian dari pemberdayaan wakaf uang sebagai landasan untuk memperkuat perekonomian dan kesejahteraan umat baik dalm segi kegiatan sosial, dakwah, peningkatan kesehatan, dan pengembangan pendidikan.

${ }^{46}$ R. Ulfiana and R.T. Yulianti, "Optimalisasi Pengelolaan Wakaf Produktif Di Majelis Wakaf Dan Kehartabendaan Pimpinan Daerah Muhammadiyah Kota Yogyakarta," Jurnal Syarikah 5, no. 2 (2019): 128.

${ }^{47}$ Herianingrum, HR, and Iswati, "Cash Waqf Empowerment Model in Improving the Quality of Education At Waqf Institutions," 34. 


\section{DAFTAR RUJUKAN}

Al-Zuhaili, Wahbah. Al-Figh Al-Islami Wa Adillatuhu. Damaskus: Dar alFikr al-Mu'asir, 1984.

Arroisi, Jarman, and Syamsuri. "Management Wakaf Pondok Modern Darussalam Gontor: Analisis Model Pemeliharaan, Pengembangan Wakaf Dan Kesejahteraan Umat." Ijtihad: Jurnal Hukum Dan Ekonomi Islam 14, no. 2 (2020).

BPS. "Statistik Indonesia Statistical Yearbook Of Indonesia 2020.” Badan Pusat Statistik, 2020.

Damanuri, Aji. "Efektivitas Dan Efisiensi Pemanfaatan Harta Wakaf Majlis Wakaf Pimpinan Daerah Muhammadiyah Ponorogo." Kodifikasia 6, no. 1 (2012).

Faisal. "Analisis Hukum Penggunaan Dana Wakaf Tunai Untuk Pembangunan Infrakstruktur." De Lega Lata: Jurnal Ilmu Hukum 5, no. 2 (2020).

Fauzi, Muhammad. "Fundraising Ziswaf Dan Kewirausahaan Di Pondok Pesantren Modern Tazakka, Batang, Jawa Tengah.” JBE Jurnal Bingkai Ekonomi 4, no. 1 (2019).

Hafidhudin, Didin. Agar Harta Berkah Dan Bertambah: Gerakan Membudayakan Zakat, Infak, Sedekah, Dan Wakaf. Jakarta: Gema Insani Press, 2007.

Hanifuddin, Iza. "Res Nullius Waqf: Dinamika Relasi Penguasaan Wilayah Oleh Negara Dan Pemilikan Aset Tanah Wakaf Oleh Umat Serta Ide Prospektif Penguatan Fungsi Dan Daya Guna Wakaf." Kodifikasia 12, no. 1 (2018).

Herianingrum, Sri, Muhammad Nafik HR, and Sri Iswati. "Cash Waqf Empowerment Model in Improving the Quality of Education At Waqf Institutions." J. Islam. Fin 2, no. 2 (2016).

Hidayanto, Fajar. "Wakaf Tunai Produktif." Mukaddimah XV, no. 26 (2009). Huda, Miftahul. "Wakaf Dan Kemandirian Pesantren Dari Tebuireng Hingga Gontor." Islamica 7, no. 1 (2012).

Huraerah, Abu. Pengorganisasian $\mathcal{E}$ Pengembangan Masyarakat. Bandung: Humaniora, 2008.

Kodifikasia: Jurnal Penelitian Islam, Volume, 15 No. 1 Tahun 2021 
Imari, Iqbal, and Syamsuri. "Pemberdayaan Wakaf Produktif Sebagai Media Pembangunan Ekonomi Pesantren.” Islamic Economic Journal, 2017.

Iskandar, Farid Izda. "Fundraising Strategy of Cash Waqf in Pondok Modern Tazakka in 2019." Journal of Islamic Economics and Philanthropy (JIEP) 02, no. 04 (2019).

Jaharuddin. "Potensi Wakaf Uang Untuk Pendidikan (Studi Kasus FEB UMJ)." Ikraith-Humaniora 2, no. 2 (2018).

https://nasional.kompas.com/read/2021/01/25/12085161/presiden-jokowiresmikan-gerakan-nasional-wakaf-uang-dan-brand-ekonomi. http:// siwak.kemenag.go.id/.

https://www.nu.or.id/post/read/24089/lembaga-wakaf-luncurkan-lumbungwakaf-uang.

http://wakaf.muhammadiyah.or.id/content-3-sdet-sejarah.html.

Manilet, Aisa. "Wakaf Tunai Dan Pemberdayaan Umat." Tahkim IX, no. 2 (2013).

Mannan. Sertifikat Wakaf Tunai, Sebuah Inovasi Instrumen Keuangan Islam. Jakarta: CIBER, 2001.

Mannan, M. Abdul. Teori Dan Praktik Ekonomi Islam. Yogyakarta: PT. Dana Bhakti Wakaf, 2002.

Mawardi, Al, and Abi al-Hasan Ali bin Muhammad bin Habib. Al Hawi Al Kabir. Beirut: Dar al Fikr, 1994.

Mohsin, Magda Ismail Abdel. "The Institution of Waqf: A Non- Profit Institution to Financing the Needy Sectors, Paper Presented to a Conference Realities"." In Research and Development: The Bridge between Ideals and Realities. IIUM International Conference on Islamic Banking and Finance, 2007.

Mu'alim, Amir. "Pengaruh Pengelolaan Wakaf Di Mesir Terhadap Pengelolaan Harta Wakaf Di Indonesia (Studi Terhadap Ijtihad Dalam Pengelolaan Wakaf Pendidikan Di UII Dan Pondok Modern Gontor)." Akademika 20, no. 1 (2015).

Munadi, Muhammad. "Pengelolaan Endowment Fund Di Perguruan Tinggi Malaysia: Studi Kasus Di Universitas Teknologi Malaysia.” Al Ulum 17, no. 2 (2017).

Mursyid, Farid Wadjdy. Wakaf Eु Kesejahteraan Umat (Filantripi Islam Yang Hampir Terlupakan). Yogyakarta: Pustaka Pelajar, 2007. 
Nasution, Mustafa Edwin. Wakaf Uang Dan Sektor Volunteer. Jakarta: Pusat Kajian Timur Tengah dan Islam Universitas Indonesia, 2005.

Prijono, Onny S., and A.M.W. Pranarka. Pemberdayaan: Konsep, Kebijakan Dan Implementasi. Jakarta: CSIS, 1996.

Qahaf, Mundzir. Sanadât Al-Ijârah, Al-Ma'had Al-Islâmy Li Al-Buhûts Wa At-Tadrîb. Cairo: Dar as-Salam, 1995.

Rachman, Puspita. "Pemberdayaan Wakaf Tunai Dalam Bidang Pendidikan Pada BMT Hidayatullah Di Surabaya." Ekonomi Dan Terapan 3, no. 8 (2016).

RI, Departemen Agama. Pedoman Pengelolaan Wakaf Tunai. Jakarta: Direktorat Jenderal Pengembangan Zakat dan Wakaf Direktorat Bimbingan Masyarakat Islam dan Penyelenggaraan Haji, 2015.

Rohmaningtyas, Nurwinsyah. "Pengumpulan Wakaf Berbasis Pesantren: Studi Kasus Di Pondok Modern Darussalam Gontor Dan Pondok Modern Tazakka." Adilla 1, no. 1 (2018).

Siddiq, Achmad. "Wakaf Produktif Dan Problematikanya Di Dunia Pesantren.” Millah XI, no. 1 (2011).

Supriyatna, Tjahta. Strategi Pembangunan Dan Kemiskinan. Jakarta: Rineka Cipta, 2000.

Syakir, Ahmad. "Pemberdayaan Ekonomi Umat Islam Indonesia Melalui Wakaf Produktif." Al-Intaj, 2016.

Syamsuri, Perdi Fauji Rohman, and Aris Stianto. "Potensi Wakaf Di Indonesia (Kontribusi Wakaf Dalam Mengurangi Kemiskinan).” Malia: Jurnal Ekonomi Islam 4, no. 1 (2020).

Syariah, Komite Nasional Keuangan. "Optimalisasi Wakaf Produktif Untuk Kesejahteraan Umat.” INSIGHT, September 2019.

Ulfiana, R., and R.T. Yulianti. "Optimalisasi Pengelolaan Wakaf Produktif Di Majelis Wakaf Dan Kehartabendaan Pimpinan Daerah Muhammadiyah Kota Yogyakarta." Jurnal Syarikah 5, no. 2 (2019).

Wijaya, Muhammad Widyarta, and Raditya Sukmana. "Peran Wakaf Produktif Dalam Pemberdayaan Kemandirian Ekonomi Pondok Pesantren (Studi Kasus Pesantren Tebuireng Yayasan Hasyim Asyari Jombang)." Teori Dan Terapan 6, no. 5 (2019).

Yaqubu, Aminu, and Azreen hamiza binti Abdul Aziz. "Implementation of Cash Waqf as a Solution for Financing Almajiri System Education 
Peran Wakaf Uang dalam Memberdayakan Pendidikan $\quad 35$ in Nigeria." International Journal of Psychosocial Rehabilitation 23, no. 4 (2019).

Yin, Robert. Studi Kasus Desain Dan Metode. Jakarta: PT Rajagrafindo Persada, 2011.

Zubaedi. Wacana Pembangun Alternatif: Ragam Prespektif Pembangunan Dan Pemberdayaan Masyarakat. Jakarta: Ar Ruzz Media, 2007. 